\title{
WAKTU TUNGGU PELAYANAN RESEP PASIEN RAWAT JALAN DI RUMAH SAKIT UMUM KOTA TANGERANG SELATAN TAHUN 2018
}

\author{
Humaira Fadhilah, Devi Novita Indriyani, Riris Andriati \\ Sekolah Tinggi Ilmu Kesehatan Kharisma Persada \\ Tangerang Selatan, 15417 \\ E-mail : Humaira.Fadhilah1@gmail.com
}

\begin{abstract}
ABSTRAK
Salah satu standar pelayanan farmasi di rumah sakit adalah waktu tunggu. Waktu tunggu pelayanan resep merupakan tenggang waktu yang diperluknan mulai resep diserahkan oleh pasien sampai dengan pasien menerima obat. Tujuan Penelitian adalah untuk mengetahui waktu tunggu pelayanan resep di Instalasi Farmasi RSU Kota Tangerang Selatan yang dibandingkan dengan standar pelayanan minimal Rumah Sakit berdasarkan Keputusan Menteri Kesehatan Republik Indonesia Nomor 129/MenkesSK/II/2008. Penelitian ini merupakan penelitian deskriptif, peneliti melakukan observasi terhadap waktu tunggu pelayanan resep. Penelitian dilaksanakan di Instalasi Famasi RSU Kota Tangerang Selatan pada bulan Maret 2018. Sampel dalam penelitian ini adalah resep yang dilayani dari pasien rawat jalan pada bulan maret 2018. Teknik pengambilan sampel sampe pada penelitian ini adalah total sampling. Sampel yang diperoleh 129 yang terdiri dari 97 resep non racikan dan 32 resep racikan. Dari penelitian ini di dapat rata - rata total waktu tunggu pelayanan resep adalah 48,37 menit untuk resep non racikan dan 173,38 menit untuk resep racikan. Kesimpulan : Rata - rata waktu tunggu pelayanan resep non racikan dan racikan belum memenuhi standar pelayanan minimal rumah sakit sesuai Kepmenkes RI No. 129 tahun 2008.
\end{abstract}

Kata Kunci: Waktu tunggu, Resep Racikan, Resep Non Racikan, Standar Pelayanan Minimal.

\section{ABSTRACT}

One of the pharmaceutical care standard in hospital is waiting time. The prescribed service waiting time is the time period under which the prescription begins to be delivered by the patient to the patient receiving the drug. The purpose of this research is to know the waiting time of prescription service at Pharmaceutical Installation of South Tangerang City General Hospital compared with minimum service standard of Hospital based on Health Minister Decree No. 129 / MenkesSK / II / 2008. This research is descriptive research, the researcher only make observation to prescription service waiting time. The research was conducted in Pharmaceutical Installation RSU South Tangerang City in March 2018. The sample in this research is recipe served from outpatient in march 2018. Sampling technique in this research is total sampling. The sample obtained 129 consisting of 97 non-prescribed recipes and 32 prescription recipes. From this study, the average total waiting time of prescription service was 48.37 minutes for non-prescribed recipes and 173.38 minutes for prescription recipe. The average waiting time for non-prescribed and concocted prescription services did not meet the minimum hospital service standards pursuant to Kepmenkes RI. 129 of 2008.

Keywords: Waiting time, Prescription recipes, Non prescribed recipes, Minimum health care standard 


\section{PENDAHULUAN}

Kesehatan merupakan kebutuhan yang paling mendasar bagi setiap manusia. Meningkatnya pengetahuan dan taraf hidup masyarakat menjadikan kesadaran masyarakat terhadap pentingnya kualitas kesehatan juga terus meningkat. Hal ini menyebabkan kebutuhan masyarakat akan sarana pelayanan kesehatan juga semakin meningkat. Salah satu dari sarana pelayanan kesehatan yang menjadi rujukan masyarakat adalah rumah sakit. Rumah sakit adalah institusi pelayanan kesehatan yang menyelenggarakan pelayanan kesehatan secara paripurna yang menyediakan pelayanan rawat inap, rawat jalan dan gawat darurat (Permenkes RI, 2014).

Instalasi Farmasi merupakan suatu unit yang memberi pendapatan yang cukup berarti untuk sebuah rumah sakit serta adanya tuntutan pasien dan masyarakat akan mutu pelayanan farmasi, mengharuskan adanya perubahan paradigma lama (drug oriented) ke paradigma yang baru (patient oriented) dengan filosofi pharmaceutical care (pelayanan kefarmasian) maka pelayanan kesehatan di rumah sakit harus selalu berbenah diri dalam meningkatkan mutu pelayanan kesehatan, salah satu hal yang menjadi indikator dalam menilai mutu pelayanan kesehatan dirumah sakit menurut dimensi pasien adalah waktu tunggu pelayanan resep di instalasi farmasi (Rakhmisari D, 2006).

Tabel 1. Indikator dan Standar untuk Pelayanan Farmasi Rumah Sakit

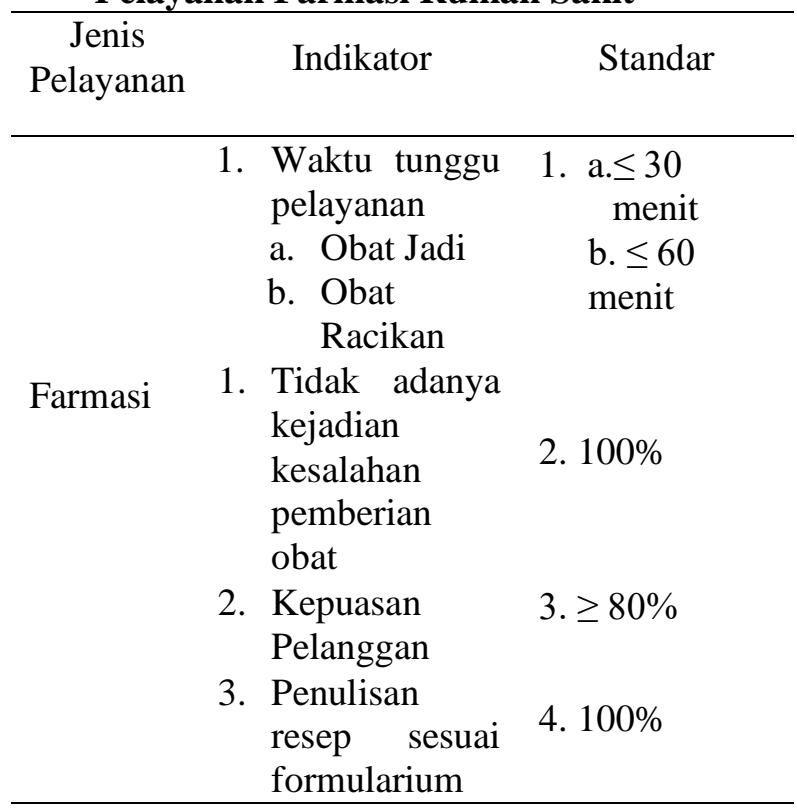

(Sumber : Kepmenkes, 2008)

Waktu tunggu pelayanan resep dibagi menjadi 2 (dua) yaitu waktu tunggu pelayanan resep obat jadi dan waktu tunggu pelayanan resep obat racikan. Waktu tunggu pelayanan resep obat jadi adalah tenggang waktu mulai pasien menyerahkan resep sampai dengan menerima obat jadi. Sedangkan waktu tunggu pelayanan resep obat racikan adalah tenggang waktu mulai pasien menyerahkan resep sampai dengan menerima obat racikan (Kepmenkes, 2008). 
Hasil dari beberapa penelitian menunjukkan bahwa waktu tunggu pelayanan resep masih lama atau belum sesuai standar pelayanan minimal yang ditetapkan oleh kementerian kesehatan seperti penelitian yang dilakukan oleh Bustani et al. (2015) waktu tunggu yaitu > 60 menit. Sedangkan penelitian yang dilakukan oleh Septini (2012) rata - rata waktu tunggu untuk resep non racikan sebesar 39 dimana 79,7\% waktu tersebut merupakan komponen delay. Sementara untuk resep racikan adalah 60,4 menit dan $59,27 \%$ dari waktu tersebut merupakan komponen delay. Hal tersebut disebabkan oleh ketersediaan obat, lama jaringan komputerisasi, beban kerja tidak sesuai dengan sumber daya manusia yang ada dan belum maksimalnya pelaksanaan prosedur pelayanan resep.

Selain itu penelitian Maharani (2015) rata - rata waktu tunggu pelayanan resep pasien rawat jalan RSUP Fatmawati sebesar 116,2 menit untuk obat non racikan dan 125,5 menit untuk resep obat racikan. Faktor yang mempengaruhi waktu tunggu pelayanan resep tersebut adalah adanya komponen delay yang lebih besar dari tindakan terutama pada proses input data dikarenakan terjadinya penumpukan resep pada saat peak hours, jumlah SDM yang belum mencukupi, SIRS (sistem informasi rumah sakit) yang belum memadai, peralatan untuk peracikan yang masih kurang dan ketersediaan ruangan yang kurang memadai.

Berdasarkan data diatas, waktu tunggu pelayanan resep di beberapa rumah sakit masih ada yang belum sesuai dengan Kepmenkes RI No. 129 Tahun 2008.

Penelitian ini bertujuan untuk mengetahui waktu tunggu pelayanan resep pasien rawat jalan RSU Kota Tangerang Selatan berdasarkan Sumber daya manusia, jenis kelamin, jabatan dan pendidikan, rata - rata waktu tunggu pelayanan, dan gambaran output (waktu tunggu).

\section{METODE}

Rancangan penelitian yang digunakan adalah penelitian observasional dan pengambilan data secara konkuren, yaitu pengambilan data penelitian dijalankan bersama dengan pelayanan dilaksanakan. Teknik pengambilan sampel dalam penelitian ini menggunakan teknik non probability sampling yaitu total sampling. Total sampling adalah teknik penentuan sampel dengan cara mengambil seluruh anggota populasi sebagai responden atau sampel.

Instrumen dalam penelitian ini adalah lembar observasi yaitu lembar pengumpul data yang berisi data nama 
pasien, waktu (pukul) penerimaan, pengerjaan resep, penyerahan obat, serta total waktu pelayanan resep (menit) dan stopwacth.

Analisis data menggunakan analisis univariat. Analisis ini umumnya hanya menghasilkan distribusi frekuensi dan presentase jumlah resep racikan da n non racikan, serta rata - rata waktu tunggu pelayanan resep racikan dan non racikan. Rata - rata dihitung dengan menggunakan rumus (mean) $: \boldsymbol{X}=\frac{\sum \mathrm{X}}{\mathrm{N}}$

$$
\begin{aligned}
& \mathrm{X}=\text { waktu rata-rata } \\
& \sum \mathrm{X}=\text { jumlah waktu pelayanan } \\
& \mathrm{N}=\text { jumlah sampel }
\end{aligned}
$$

\section{HASIL}

Tabel 2. Sumber Daya Manusia di Instalasi Farmasi RSU Kota Tangerang Selatan

\begin{tabular}{ccc}
\hline Jenis Kelamin & Jabatan & Pendidikan \\
\hline Laki - Laki & Kepala Instalasi Farmasi & Apoteker \\
\hline Laki - Laki & Pelaksana (APA Pendamping) & Apoteker \\
\hline Perempuan & Pelaksana (APA Pendamping) & Apoteker \\
\hline Perempuan & Pelaksana (APA Pendamping) & Apoteker \\
\hline Perempuan & Pelaksana (APA Pendamping) & Apoteker \\
\hline Perempuan & Pelaksana (APA Pendamping) & Apoteker \\
\hline Perempuan & Pelaksana (APA Pendamping) & Apoteker \\
\hline Perempuan & Pelaksana (AA) & D3 Farmasi \\
\hline Perempuan & Pelaksana (AA) & D3 Farmasi \\
\hline Perempuan & Pelaksana (AA) & SMF \\
\hline Perempuan & Pelaksana (AA) & SMF \\
\hline Perempuan & Pelaksana (AA) & SMF \\
\hline Perempuan & Pelaksana (AA) & SMF \\
\hline Laki - Laki & Pelaksana (AA) & S1 Famasi \\
\hline Laki - Laki & Pelaksana (AA) & SMF \\
\hline Laki - Laki & Pelaksana (AA) & SMFsana (AA) \\
\hline Laki - Laki & PMF & \\
\hline
\end{tabular}

Sumber : Data Primer, 2018 
Manajemen rumah sakit dibagian instalasi farmasi dikepalai oleh seorang apoteker yang mengkoordinasikan kegiaan pelayanan resep sesuai dengan prosedur pelayanan. Petugas - petugas APA Pendamping dan AA dalam melaksanakan pekerjannya dibagi menjadi 2 shift untuk APA pendamping dan 4 shift untuk AA, kecuali koordiator pelayanan farmasi klinis hanya bertugas di pagi hari sesuai jam kerja yaitu 07.00 $14.00 \mathrm{WIB}$.

Tabel 3. Jumlah Sampel Berdasarkan Jenis Resep Racikan dan Non Racikan yang dilayani di Rawat Jalan RSU Kota Tangerang Selatan

\begin{tabular}{cccc}
\hline No & Jenis Resep & Jumlah Sampel & Presentasi \\
\hline 1 & Racikan & 32 Resep & $24,8 \%$ \\
2 & Non Racikan & 97 Resep & $75,2 \%$ \\
\hline & Total & 129 Resep & $100 \%$
\end{tabular}

Sumber : Data Primer, 2018

Dari hasil penelitian, didapat dari 97 resep non racikan $(75,2 \%)$ dan 32 jumlah sampel dalam penelitian resep racikan $(24,8 \%)$. berdasarkan jenis resep 129 resep, terdiri

Tabel 4. Rata - rata waktu tunggu pelayanan resep di rawat jalan RSU Kota Tangerang Selatan

\begin{tabular}{|c|c|c|c|c|c|c|c|}
\hline \multicolumn{8}{|c|}{ Resep Diterima Pada Pukul } \\
\hline & & \multicolumn{2}{|c|}{$09.00-11.00$} & \multicolumn{2}{|c|}{$11.00-13.00$} & Total & \\
\hline Hari & Jenis Resep & $\begin{array}{l}\text { Jumlah } \\
\text { Resep }\end{array}$ & $\begin{array}{l}\text { Waktu } \\
\text { Tunggu } \\
\text { (menit) }\end{array}$ & $\begin{array}{l}\text { Jumlah } \\
\text { Resep }\end{array}$ & $\begin{array}{l}\text { Waktu } \\
\text { Tunggu } \\
\text { (menit) }\end{array}$ & $\begin{array}{l}\text { Jumlah } \\
\text { Resep }\end{array}$ & $\begin{array}{l}\text { Waktu Tunggu } \\
\text { (menit) }\end{array}$ \\
\hline \multirow[t]{2}{*}{ Senin } & Non Racikan & 10 & 36,24 & 9 & 39,43 & 19 & 37,75 \\
\hline & Racikan & 4 & 52,35 & 3 & 60,55 & 7 & 55,86 \\
\hline \multirow[t]{2}{*}{ Selasa } & Non Racikan & 7 & 26,16 & 4 & 29,1 & 11 & 27,22 \\
\hline & Racikan & 3 & 61,5 & 2 & 65,6 & 5 & 63,14 \\
\hline \multirow[t]{2}{*}{ Rabu } & Non Racikan & 12 & 25,33 & 8 & 31,56 & 20 & 27,82 \\
\hline & Racikan & 5 & 40,81 & 3 & 57,43 & 8 & 47,04 \\
\hline \multirow[t]{2}{*}{ Kamis } & Non Racikan & 13 & 24,05 & 10 & 31,51 & 23 & 27,29 \\
\hline & Racikan & - & - & 5 & 56,57 & 5 & 56,57 \\
\hline \multirow[t]{2}{*}{ Jumat } & Non Racikan & 8 & 18,53 & 4 & 22,03 & 12 & 19,69 \\
\hline & Racikan & 2 & 59,56 & 2 & 61,42 & 4 & 60,49 \\
\hline \multirow[t]{2}{*}{ Sabtu } & Non Racikan & 7 & 15,56 & 5 & 18,14 & 12 & 16,63 \\
\hline & Racikan & - & - & 3 & 42 & 5 & 42,00 \\
\hline & & \multirow{2}{*}{\multicolumn{2}{|c|}{ Total }} & Non Ra & & 97 & 48,37 \\
\hline & & & & Racikan & & 32 & 173,38 \\
\hline
\end{tabular}

Sumber : Data Primer, 2018

Hasil dari penelitian ini total waktu tunggu pelayanan resep di instalasi farmasi RSU Kota Tangerang Selatan untuk resep non racikan yaitu 48,37 menit 
dan untuk resep racikan adalah 173,38 menit. Dan untuk waktu tunggu resep pada hari sabtu tidak terlalu lama karena

\section{DISKUSI}

Berdasarkan tabel 1 dapat diketahui hasil dari sumber daya manusia di Instalasi Farmasi RSU Kota Tangerang Selatan total sumber daya manusia yaitu 17 orang dengan jabatan dan pendidikan yang berbeda. Kepala instalasi dikepalai oleh 1 orang Apoteker dan didampingi oleh 6 Apoteker pendamping. Dalam instalasi farmasi dibantu oleh 10 Asisten apoteker. Hasil penelitian ini sama dengan hasil penelitian yang dilakukan oleh Aida Maftuhah di Depo Farmasi RSUD Gunung Jati Cirebon yang menyatakan bahwa jumlah sumber daya manusia di depo farmasi RSUD Gunung Jati Cirebon petugas terdiri dari 1 orang apoteker, 6 orang tenaga teknis kefarmasian (Aida Maftuhah dkk, 2016). Hasil penelitian yang dilakukan oleh Yulia Elizabet di Instalasi rawat jalan RS Karya Bakti Pratiwi Bogor menyatakan sumber daya manusia di instalasi rawat jalan RS Karya Bhakti Pratiwi yang berkaitan dengan pelayanan resep rawat jalan ada 12 orang terdiri dari 1 orang apoteker sebagai penanggung jawab depo farmasi rawat jalan, 11 Asisten apoteker dimana 3 diantaranya merupakan asisten apoteker pada hari sabtu jumlah resep lebih sedikit daripada hari lainnya.

baru yang masih dalam masa orientasi (Yulia Elizabet, 2016).

Sumber Daya Manusia di Instalasi Farmasi RSU Kota Tangerang Selatan berdasarkan Permenkes No 56 tahun 2014 tentang Klasifikasi dan Perizinan Rumah Sakit, SDM Rumah sakit Umum kelas C untuk tenaga kefarmasian yang bertugas di rawat jalan yaitu 1 (satu) orang apoteker sebagai koordinator penerimaan, distribusi dan produksi yang dapat merangkap melakukan pelayanan farmas klinik di rawat inap atau rawat jalan dan dibantu oleh tenaga teknis kefarmasian yang jumlah disesuaikan dengan beban kerja pelayanan rumah sakit. Sumber daya manusia RSU Kota Tangerang Selatan sudah memadai (Permenkes, 2014).

Berdasarkan tabel 2 jenis resep yang dilayani di Instalasi Farmasi rawat jalan RSU Kota Tangerang Selatan terdiri dari 129 resep yaitu 32 resep racikan $(24,8 \%)$ dan 97 resep non racikan $(75,2 \%)$. Hal ini sesuai dengan penelitian yang dilakukan Karuniawati didapat jumah resep obat jadi sebanyak 147 resep lebih banyak daripada resep racikan sebanyak 78 resep (Karuniawati dkk, 2016). Dari hasil penelitian yang dilakukan, jenis resep juga 
mempengaruhi lama waktu tunggu pelayanan resep. Resep dibedakan atas resep non racikan dan resep racikan. Resep racikan selain menyiapkan obat, juga harus melakuan perhitungan obat, dan meracik obat sesuai dengan permintaan resep dengan memperhatikan sifat dan jenis obat.

Berdasarkan tabel 3, rata-rata waktu tunggu pelayanan resep di Instalasi farmasi RSU Kota Tangerang Selatan untuk resep non racikan 48,37 menit dan resep racikan 173,38 menit. Rata-rata waktu tunggu resep non racikan dan resep racikan belum memenuhi standar waktu tunggu pelayanan resep sesuai dengan Kepmenkes No. 129 tahun 2008 standar pelayanan resep yaitu untuk resep non racikan $\leq 30$ menit dan resep racikan $\leq 60$ menit (Kepmenkes, 2008).

Resep yang memenuhi standar waktu tunggu pelayanan resep di RSU Kota Tangerang Selatan sebanyak 60 resep non racikan dan 22 resep racikan. Resep tersebut merupakan resep yang diterima pada pukul 09.00 - 11.00 WIB dan seluruh resep pada hari sabtu ratarata waktu tunggu pelayanan sudah memenuhi syarat yaitu 16,63 menit untuk resep non racikan $(\leq 30$ menit) dan 42 menit untuk resep racikan ( $\leq 60$ menit). Hal ini disebabkan karena belum ada penumpukan resep dan jumlah resep pada hari sabtu lebih sedikit dibandingkan dengan hari lain.

Rata - rata waktu tunggu pelayanan resep racikan dan non racikan belum sesuai dengan standar pelayanan resep karena masih terdapat beberapa resep yang melebihi standar waktu tunggu pelayanan. Hal ini disebabkan karena resep di instalasi farmasi RSU Kota Tangerang Selatan mengalami delay karena terjadi penumpukan resep.

\section{SIMPULAN}

Hasil penelitian yang dilakukan di instalasi farmasi RSU Kota Tangerang Selatan tentang waktu tunggu pelayanan resep yang didasari oleh Keputusan Menteri Kesehatan Republik Indonesia Nomor 129 Tahun 2008 tentang Standar Pelayanan Minimal Rumah Sakit dapat disimpulkan yaitu Sumber daya manusia, petugas kefarmasian sudah memadai. Jenis resep yang ada di instalasi farmasi berjumlah 129 resep yang terdiri dari $75,2 \%$ resep non racikan dan $24,8 \%$ resep racikan. Rata-rata waktu tunggu pelayanan resep non racikan 48,37 menit dan resep racikan 183,38 menit. Hal ini menunjukkan bahwa rata - rata waktu tunggu pelayanan resep belum memenuhi standar pelayanan minimal waktu tunggu pelayanan resep non racikan $\leq 30$ menit dan untuk resep racikan $\leq 60$ menit. 


\section{DAFTAR PUSTAKA}

Aryani, F., Angraini, D. \& Yani, N.P. 2014. Evaluasi Mutu Pelayanan Kefarmasian Kategori Waktu Tunggu Pelayanan Resep di Depo Rawat Jalan Rumah Sakit Umum Daerah Arifin Achmad Pekanbaru.

Bustani, N.M, Rattu, A.J.\& Saerang, J.S.M. 2015. Analisis Lama Waktu Tunggu Pelayanan Pasien Rawat Jalan Propinsi Sulawesi Utara.

Kurniawati, dkk. 2016. Evaluasi Pelaksanaan Standar Pelayanan Minimal (SPM) Farmasi Kategori Lama Waktu Tunggu Pelayanan Resep Pasien Rawat Jalan Di RSUD Kota Salatiga Tahun 2016. Jurnal Imiah Farmasi. Universitas Muhammadiyah Surakarta.

Kepmenkes. 2008. Keputusan Menteri Kesehatan Republik Indonesia Nomor 129/MENKES/SK/II/2008 Tentang Standar Pelayanan Minimal Rumah Sakit. Jakarta: Depkes RI.

Permenkes. 2014. Peraturan Menteri Kesehatan Republik Indonesia Nomor 56 Tahun 2014 Tentang Klasifikasi dan Perizinan Rumah Sakit. Jakarta: Depkes RI.

Rakhmisari, D. 2006. Manajemen Instalasi Farmasi Rumah Sakit. Program Diploma III Perumahsakitan FKUI. Jakarta.

Maharani, Anisa Ega. 2015. Gambaran Waktu Tunggu Pelayanan Resep Pasien BPJS Pada Peak Hours Di Depo Farmasi Instalasi Rawat Jalan RSUP Fatmawati Tahun 2015. Skripsi UI. Depok.

Septini, Renni. 2012. Analisis Waktu Tuggu Pelayanan Resep Pasien Askes Rawat Jalan di Yanmsum Farmasi RSPAD Gatot Subroto Tahun 2012. Skripsi. Depok.

Yulia, E. 2016. Gambaran Sistem Pelayanan Resep Pasien Di Instalasi Farmasi Rawat Jalan RS Karya Bhakti Pratiwi Bogor Tahun
2016.Skripsi. Jakarta. Universitas Islam Negeri Syarif Hidayatullah. 